\title{
Influence of Tow Architecture on Compaction and Nesting in Textile Preforms
}

\author{
Z. Yousaf ${ }^{1} \cdot$ P. Potluri $^{1} \cdot$ P. J. Withers ${ }^{2}$
}

Received: 21 September 2016 / Accepted: 26 October 2016/Published online: 14 November 2016

(C) The Author(s) 2016. This article is published with open access at Springerlink.com

\begin{abstract}
Transverse compression response of tows during processes such as vacuum infusion or autoclave curing has significant influence on resin permeability in fabrics as well as the laminate thickness, fibre volume fraction and tow orientations in the finished composite. This paper reports macro -scale deformations in dry fibre assemblies due to transverse compaction. In this study, influence of weave geometry and the presence of interlacements or stitches on the ply-level compaction as well as nesting have been investigated. 2D woven fabrics with a variety of interlacement patterns - plain, twill and sateen- as well as stitched Non-crimp (NCF) fabrics have been investigated for macro-level deformations. Compression response of single layer and multilayer stacks has been studied as a function of external pressure in order to establish nesting behaviour. It appears that the degree of individual ply compaction and degree of nesting between the plies are influenced by tow architectures. Inter-tow spacing and stitching thread thickness appears to influence the degree of nesting in non-crimp fabrics.
\end{abstract}

Keywords Compaction - Weave architecture - Glass fibre reinforced composites · Nesting $\cdot$ Noncrimp fabrics

\section{Introduction}

Low-cost composite manufacturing techniques based on resin infusion of dry textile preforms are becoming increasingly popular in the aerospace, automotive and energy sectors. In these processes, several fabric plies are draped on the tool surface and subjected to transverse compaction forces either by vacuum (Vacuum Infusion) or

\section{Z. Yousaf}

zeshan.yousaf@manchester.ac.uk

1 Robotics and Textile Composite Group, Northwest Composite Centre, School of Materials, University of Manchester, Manchester M13 9PL, UK

2 Manchester X-ray Imaging Facility, School of Materials, University of Manchester, Manchester M13 9PL, UK 
external pressure (as in resin transfer moulding), and at the same time infused with liquid resin. Compaction of the preform changes the thickness and thereby the ultimate fibre volume fraction of the composite laminate. Preform compaction also changes the tow waviness, which in turn influences the mechanical properties of the composite [1]. Furthermore, the compaction of the preform affects its permeability to resin flow [2]. During autoclave curing, significantly higher pressures (around 7 bar) are applied resulting in a reduction in thickness and a corresponding increase in fibre volume fraction. As a result it is important to characterise the compaction behaviour during the composite manufacturing process [3].

Extensive research work has been reported in the literature on the compaction behaviour of different fabrics [4-15]. Van Wyk [16] was probably one of the first researchers to treat the fibres under compression as a system of bending units. A typical pressure-thickness curve (Fig. 1) was given by Mastudaira and Qin [5]. The curve comprises three parts, two linear and one exponential part (Fig. 1).

The effect of the reinforcement architecture on the compaction behaviour has been studied by various researchers [8, 13, 17-19]. Experimental research on the compression of plain weave fabric can be found in previous literature $[4,8,11,17,20,21]$. The compression response of non-crimp stitched fabrics has also been reported [22-25]. The compression response of multilayer preforms differs from that of a single layer due to the opportunity of nesting of the layers. The nesting behaviour was discussed by Lomov et al. [26]. Resin permeability through fabrics due to the nesting effect has been studied by various researchers [27-29]. It was observed by Hoes et al. that nesting is a major source of variation in experimentally determined permeability values [30]. The nesting of layers has been studied in terms of a nesting factor [31] and a nesting coefficient [32]. The majority of the existing literature is focused on plain weave, with scant focus on the influence of interlacement architecture on compaction behaviour. The use of commercial fabrics in previous compaction studies has meant that it has not been possible to control the weave parameters. In this study, several weave architectures were produced on a rapier loom so as to keep the remaining parameters such as intertow spacing and tow linear density constant. This procedure enabled us to systematically study the influence of interlacement geometry on compaction behaviour, while keeping all the other parameters constant.

Fig. 1 Typical pressure thickness curve [5]

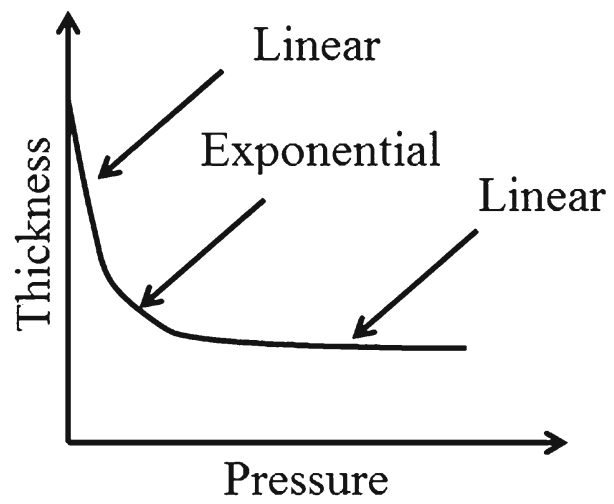




\section{Material \& Experimental details}

\subsection{Materials}

In this study, woven fabrics including plain (1/1), twill (3/1) and 5-Harness sateen weaves with 600 tex yarn of average fibre diameter 16 micron, E-glass yarn in both warp and weft directions have been produced at the University of Manchester. In addition, $0^{\circ}, 90^{\circ}$ and $\pm 45^{\circ}$ non-crimp carbon fibre fabrics with $12 \mathrm{~K}$ yarn with fibre diameter of 7 micron, produced by Sigmatex have been included in the study. In both cases, the plies were stitched together using a polyester thread.

The fabrics were manufactured such that the yarn linear density (Tex) and inter-tow spacing (ends or picks/cm) were identical for plain, twill and sateen fabrics. In this way the influence of weave style on the compaction behaviour can be studied. The specifications of the fabrics, used are listed in Tables 1 and 2. The repeats of the plain, twill, sateen and NCF are as shown in Fig. 2; the images were created using the TexGen software developed by University of Nottingham. The optical images of woven fabrics and non-crimp stitched carbon fabrics are presented in Fig. 3.

\subsection{Experimental Methodology}

\subsubsection{Mechanical Testing}

Transverse compression testing of single and multilayer fabrics was conducted using an Instron 5569 universal testing machine (Fig. 4) with a small-capacity load cell $(5 \mathrm{kN})$. The surface areas of the top and the botton plates were $50 \mathrm{~cm}^{2}$. The fabric samples were cut into $10 \mathrm{x} 10 \mathrm{~cm}$ pieces. As the fabric thickness is small in comparison to the machine stroke, the accuracy with which the compression strain is measured becomes important. In order to minimise errors, machine compliance as a function of the applied load was measured and accounted for in the fabric strain calculations. Continuous testing method was adopted for compression testing. In the continuous testing method, the cross-head was moved continuously at $1 \mathrm{~mm} / \mathrm{min}$ and the resulting pressure - thickness curve was recorded.

\section{Results}

\subsection{Analysis of Macro-Scale Deformations}

\subsubsection{Woven Fabrics}

Fabric compaction tests were performed on single layers, as well as on stacks of four and six layer. Figure 5 shows the pressure - thickness curves for single layer plain, twill and sateen

Table 1 Woven fabric specifications

\begin{tabular}{lllllll}
\hline Sample \# & Yarn count & Type & Weave & Ends/cm & Picks $/ \mathrm{cm}$ & $\begin{array}{c}\text { Areal weight } \\
\left(\mathrm{g} / \mathrm{m}^{2}\right)\end{array}$ \\
\hline WV-1 & 600 Tex & E-glass & 1/1 Plain & 4.8 & 4.4 & 548 \\
WV-2 & 600 Tex & E-glass & 3/1 Twill & 4.8 & 4.4 & 546 \\
WV-3 & 600 Tex & E-glass & 5H Sateen & 4.8 & 4.4 & 545 \\
\hline
\end{tabular}


Table 2 Stitched non-crimped fabric (NCF) specifications

\begin{tabular}{llllll}
\hline Sample & Yarn count & Plies orientation & Tows $/ \mathrm{cm}$ & Stitch yarn & $\begin{array}{l}\text { Arial weight } \\
(\mathrm{g} / \mathrm{m} 2)\end{array}$ \\
\hline $\mathrm{NCF}-1$ & $12 \mathrm{k}$-carbon & $+45^{\circ}$ & $1.5 / 1.5$ & 55 dtex (polyester) & 246 \\
$\mathrm{NCF}-2$ & $12 \mathrm{k}$-carbon & $0^{\circ}, 90^{\circ}$ & $2.5 / 2.5$ & 80 dtex (polyester) & 550 \\
\hline
\end{tabular}

fabrics. It was observed that for single layers, the thickness of the plain woven fabric was the lowest of the three weaves, under a very small load with the twill and sateen weaves having nearly the same thickness (Fig. 5).

Naturally, the thickness of all the fabrics decrease with increasing pressure and at a pressure of $20 \mathrm{kPa}$, the sateen fabric thickness became less than the twill fabric and by a pressure of 30 $\mathrm{kPa}$, the sateen weave has become the thinnest. Upon further increasing the pressure the plain fabric becomes the most resistant to deformation. The plain fabric may have the lowest initial thickness due to having the highest number of interlacement points compared to the twill and sateen fabrics. Interlacements in the plain weave result in higher inter-tow compaction forces and hence lower initial thickness. The twill and sateen fabrics have fewer interlacements per unit area and hence a higher initial thickness. During compression, the plain weave offers the greatest resistance due to the tightness of the weave. Chen et al. [13] attributed this to the bending stiffness of the interlacing tow segments. Of the two remaining structures, the sateen weave has the fewest interlacements and hence the highest reduction in thickness.

In the case of multilayer preforms, stacks of two and six layers were tested for plain, twill and sateen fabrics. The average layer thickness results against different pressures are presented in Fig. 6 along with single-layer curves. From Fig. 6, it can be seen that there is a reduction in the average layer thickness of all these fabrics with increasing number of layers, which is considered to be due to nesting of the layers [8]. This observation of reduction of average layer thickness with increasing number of layers is in agreement with the literature $[7,11,17,26]$. It can be seen from Fig. 6 that highest thickness reduction amongst all weaves occurred in plain
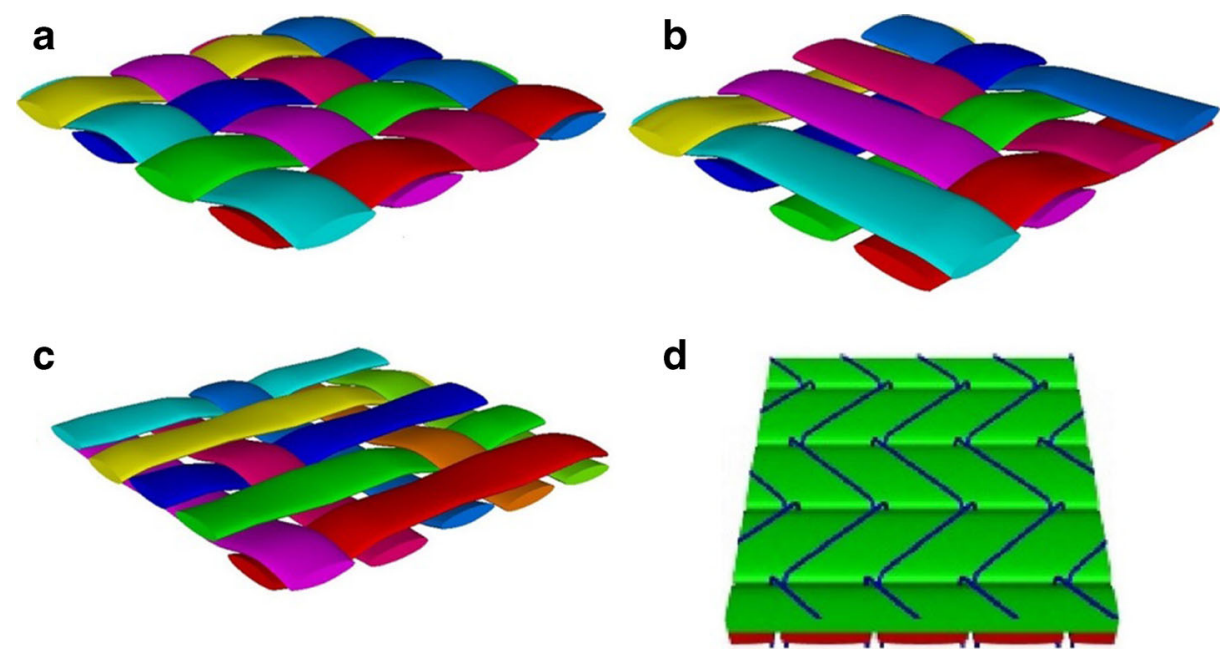

Fig. 2 Fabrics styles a Plain, b 3/1 twill, c 5H sateen and d NCF 


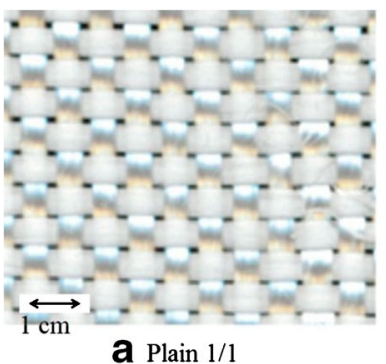

a Plain $1 / 1$

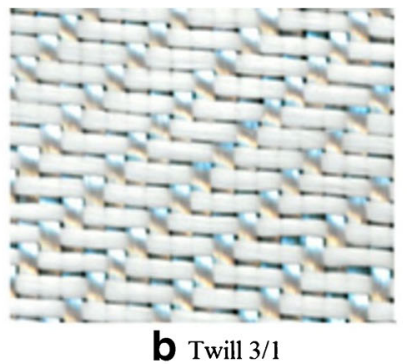

b Twill 3/1

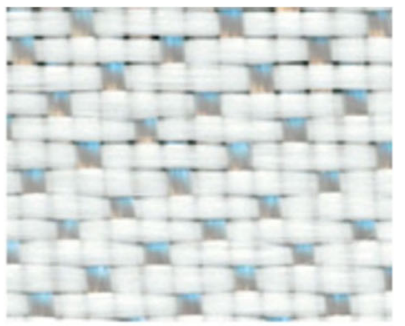

C 5 Harness sateen

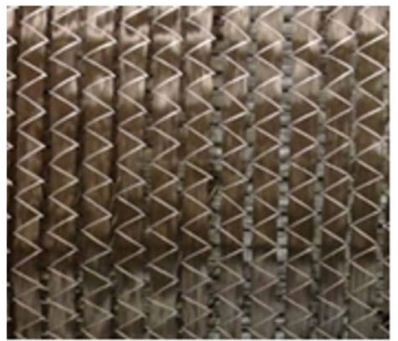

d 0,90

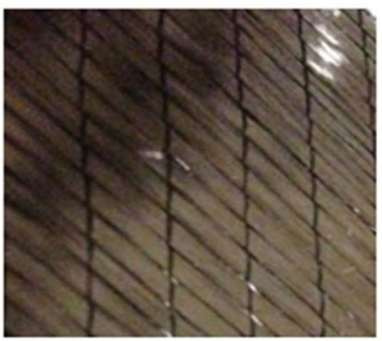

e $+45 /-45$

Fig. 3 Optical images of the glass woven and non-crimp carbon fibre stitched fabrics studied

woven fabric stacks of two and six layers as compared with its single layer which is due to nesting of the layers in plain woven. Compared to single layer thickness of respective weaves, $10 \%$ higher thickness reduction was observed in average layer thickness of 2 layer plain woven fabric whereas thickness reduction was $4 \%$ higher in 2 layer sateen fabric at pressure of $600 \mathrm{kPa}$. In case of six layer stacks, again highest average layer thickness reduction was observed in plain woven fabric $(23 \%)$ compared to single layer thickness of plain fabric at pressure of $600 \mathrm{kPa}$, while least average layer thickness reduction $(15 \%)$ was observed in 6 layer stack of sateen fabric in comparison to single layer sateen. The reductions in average layer thickness of 2 and 6 layer stacks of twill weave fabrics in comparison with the single layer thickness were $8 \%$ and $16 \%$, respectively. The highest reduction in average layer thickness of plain woven fabric compared to its single layer with increase in number of layers

Fig. 4 Ex situ transverse compression set up

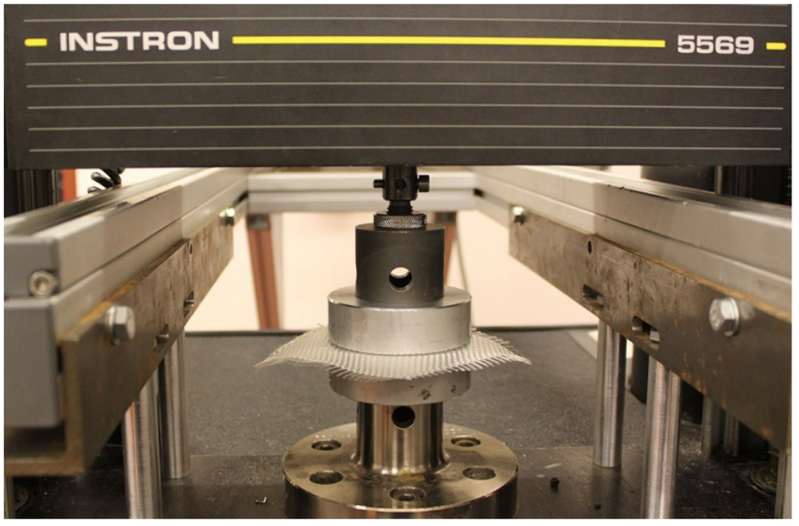


Fig. 5 Single layer thickness results against pressure

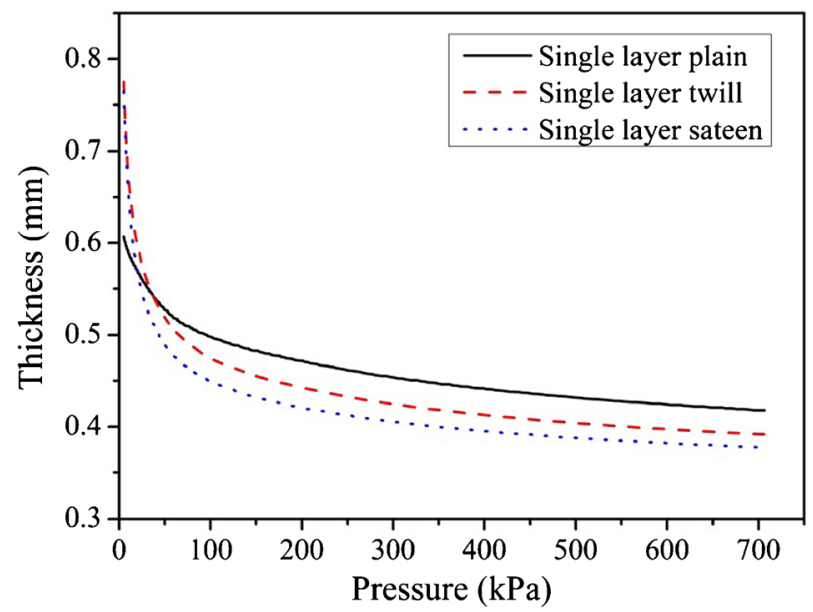

shows that layers nest better in plain fabric compared to twill and sateen fabrics which is in accordance with the previous study [26].

As one would expect from Fig. 7, at zero load the multi-layer plain weave has the lowest thickness. Further the results for the different multilayer fabrics are qualitatively the same as for the single layer ones. With increasing pressure, the rate of reduction in thickness was least for the plain fabric and highest for the sateen fabrics giving rise to the lowest fibre volume fraction in plain fabrics compared to twill and sateen fabrics at high pressures. Comnsequently, the thickness of the twill and sateen weaves is almost $20 \%$ higher than the plain weave at a pressure level of $5 \mathrm{kPa}$ for two and six layers stacks. In the case of the two-layer stacks, the thickness of the sateen and twill fabrics became smaller than that of the plain weave at pressures greater than $25 \mathrm{kPa}$ and $35 \mathrm{kPa}$ respectively, whereas in the case of the six layer stacks, considerably higher pressures of $57 \mathrm{kPa}$ and $85 \mathrm{kPa}$ were required respectively before the thickness of the sateen and twill fabrics become equal to that of the plain weave fabric. From Fig. 7, it can be seen that beyond pressure of $100 \mathrm{kPa}$, the thickness reduction is least in plain fabric stacks compared to twill and sateen fabrics which can be attributed to the least bending deformation of tows in plain fabric due to its tight structure.

This observation of least stack thickness reduction in plain fabric is in contradiction to the study of Saunders et al. [17], in which they found twill fabric to be the most resitant to compression compared to plain and sateen fabrics. But in their study, the yarn densities and the counts were not same for all the three type of weaves which could result in different compaction behaviour of these fabrics. Overall, from single layer and multilayer fabric study of plain, twill and sateen structures under compaction, it was seen that the plain fabric is the most compression resistant due to its tight structure and consequently it results in the lowest fibre volume fraction at a given pressure even though the pressures are characteristically low $(<100 \mathrm{kPa})$ for vacuum infusion as shown in the Fig. 8 . The fibre volume fractions for the plain weave fabric are higest at the start of loading and as the pressure increases, the fibre volume fraction of twill and sateen fabrics become higher than plain woven fabric. The reason of the higher fibre volume fraction at initial loading point is the lower thickness of plain woven fabric at that stage. From Fig. 8, it can also be seen that fibre volume fraction of the three structures increases with increase in number of layers which is due to nesting of layers in multilayer stack $[8,11,26]$. 
Fig. 6 Compression behaviour of multi-layer fabrics for a plain, $\mathbf{b}$ twill, c sateen
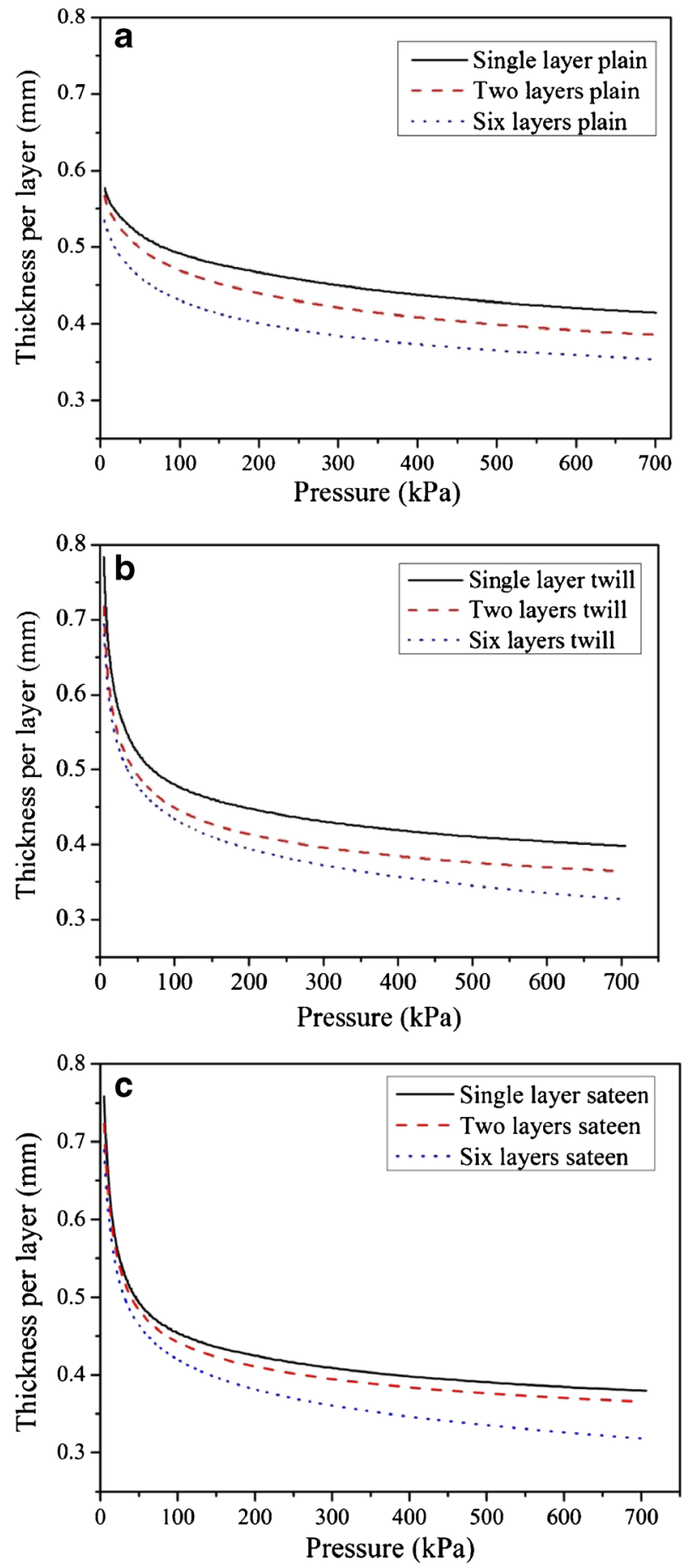
Fig. 7 The variation in layer thickness as a function of pressure for a two layers b six layer stacks
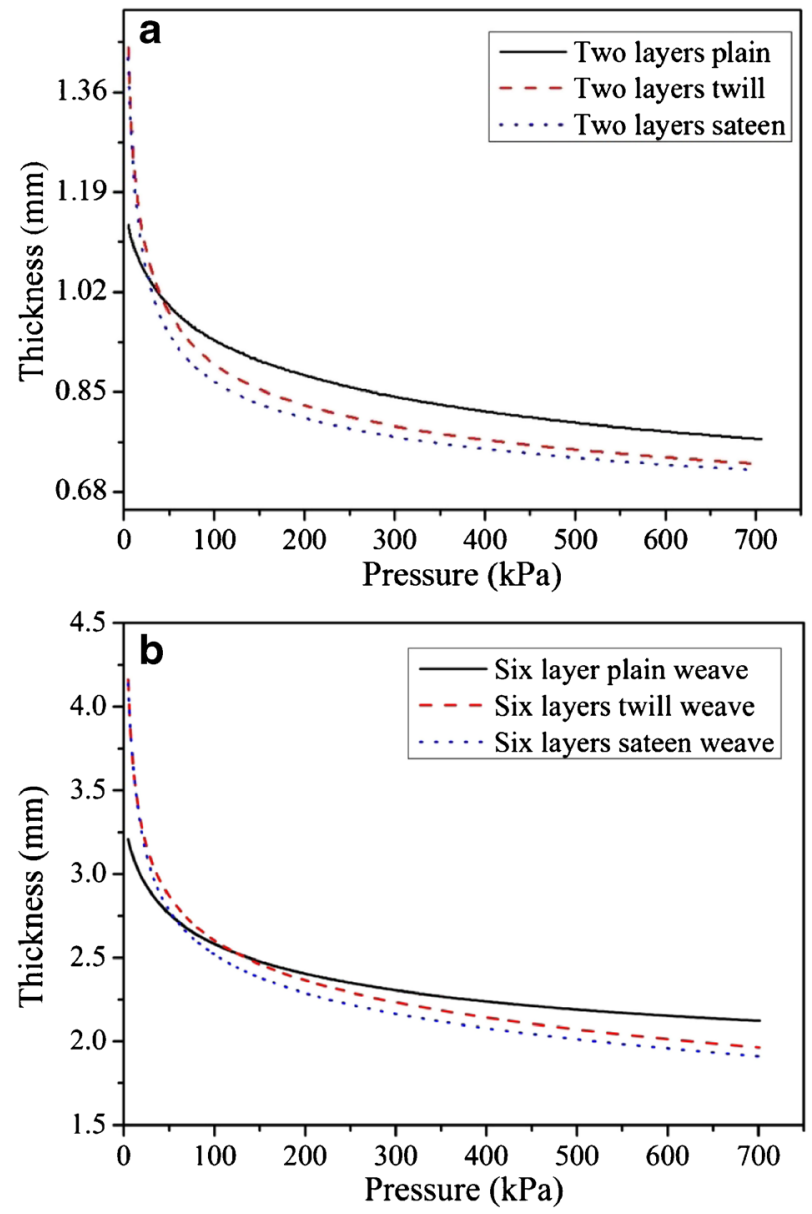

\subsubsection{Non- Crimp Fabrics}

The pressure thickness results for the two non-crimped sticthed carbon fabrics are presented in Fig. 9.

Similar to woven fabrics, thickness of NCF fabrics also decreased with application of pressures. For NCF-1 $\left( \pm 45^{\circ}\right)$, it is evident that there was a reduction in the average layer
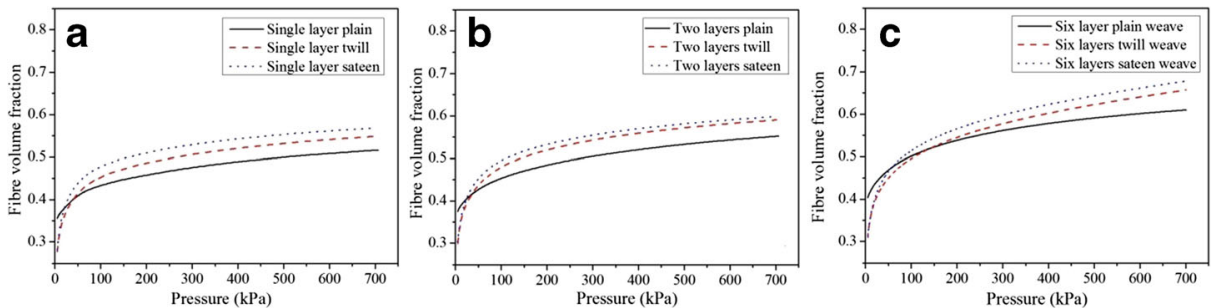

Fig. 8 Fibre volume fraction of plain, twill and sateen fabrics for a single layer, $\mathbf{b}$ two layers and $\mathbf{c}$ Six layers 
Fig. 9 Non-crimp carbon fibre fabric thickness variations as a function of pressure, $\mathbf{a} \pm 45^{\circ}, \mathbf{b}$ $0^{\circ}, 90^{\circ}$
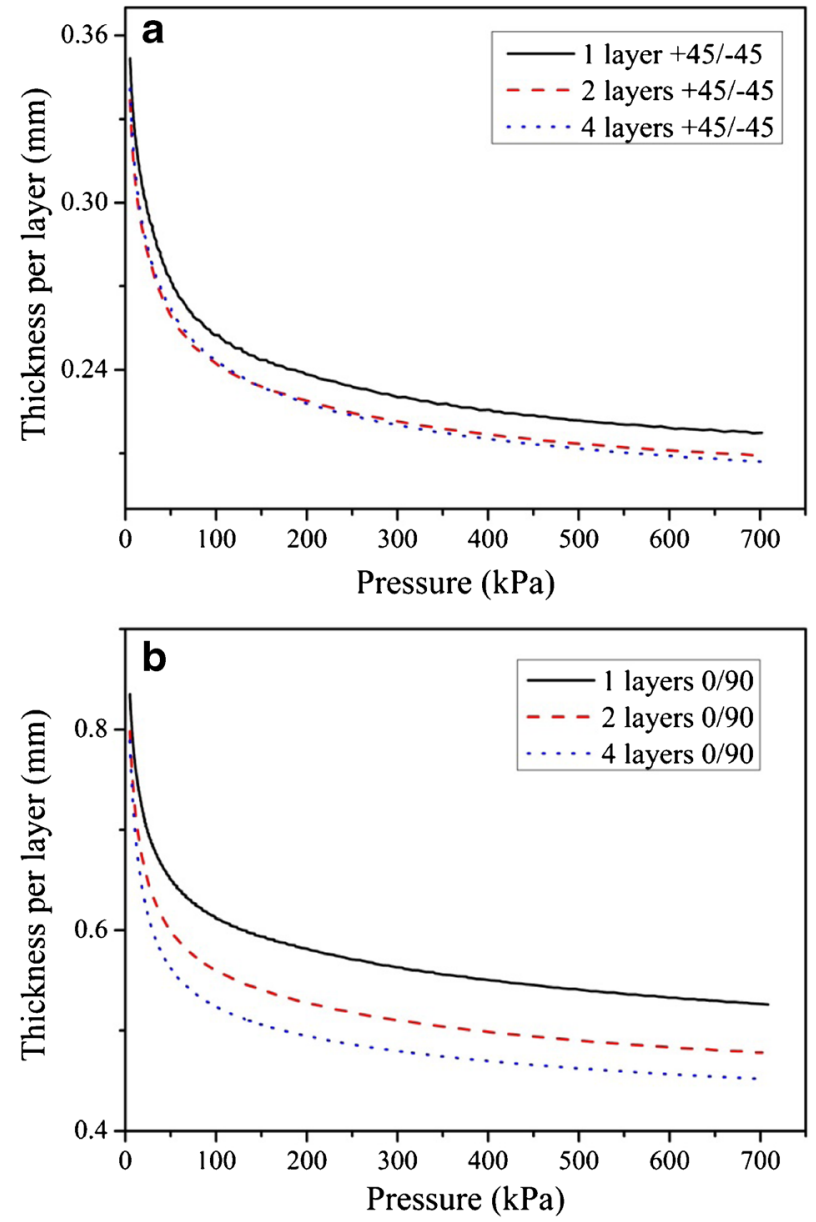

thickness upon movimg from a single layer to 2 but that the addition of further layers resulted in only a marginal decrease in thickness. In the case of NCF- $2\left(0^{\circ}, 90^{\circ}\right)$, the thickness reduction with increasing number of layers was more marked. This can be explained by the fact that in non-crimp stiched fabrics, the thickness reduction in multilayer fabrics is supported by presence of stitched yarn on the fabric surface which allow the layer surface to nest with each other [26]. Coarse stitch yarn on the fabric surface will support higher nesting than fine stitch yarn. In NCF-2 the stitched yarn has a corser count compared to NCF-1 due to which the nesting might be higher in NCF-2 resutling into higher thickness reduction in multilayer stack. Also in NCF-2, the thread density is higher than NCF-1 and higher thread desnity can make the tows round shape in NCF-2 increasing inter-tow nesting and consequently larger thickness reduction in NCF-2 on adding number of layers. For non-crimp stitched fabrics, different compaction behaviours were observed in literature. Only a small thickness reduction was noticed in stitched non-crimp fabrics for both $0^{\circ}, 90^{\circ}$ and $\pm 45^{\circ}$ by Hammani [18] while the thickness reduction was found to be higher in the $0 \%-45^{\circ} / 90^{\circ},+45^{\circ}$ plies compared to $\pm 45^{\circ}$ plies [22]. Saunders et al. [17] observed that non-crimp stitched bonded fabrics are easier to deform compared to plain and sateen fabrics. Fibre volume fraction of NCF fabrics are 
presented in Fig. 10. It is evident from Fig. 10 that fibre volume fraction of NCF fabrics increase with adding number of layers but effect of increasing layers on fibre volume fraction is more prominent in $0^{\circ}, 90^{\circ}$ and the reason can be returned to thickness changes in $0^{\circ}, 90^{\circ}$ and $\pm 45 \mathrm{NCF}$ fabrics as discussed earlier.

\subsection{Nesting of Layers}

During composite manufacturing, fabric layers are draped on the mold surface and compacted to a certain level of pressure. The fabric layers in a multilayer stack are placed on top of each other. If the fabric layers sit exactly on top of each other without shifting (Fig. 11a), there is no nesting of individual layers but if there is a shifting of layers, the fabric plies nest with each other during compression (Fig. 11b).

Layer nesting describes how the "hills" and "valleys" of two adjacent layers embed one into another reducing the average layer thickness relative to that of an individual layer [32]. The nesting of the layers is quantified in terms of the nesting coefficient [32] or nesting factor [31]. The nesting factor can be calculated using the following equation [31].

$$
N F={ }^{T} / \sum_{i=1}^{n} T i
$$

where $N F$ is the nesting factor, $T$ the stack thickness and $T i$ the individual layer thickness. If the layers sit upon each other without nesting, the thickness of the two layers stack will be equal to sum of the individual layer thickness and the nesting factor will be one. But in the case where the layers shift and come closer to each other, the nesting factor will be less than one and the thickness of the stack will be smaller than the sum of the thickness of the individual layers such that a lower nesting factor indicates more efficient nesting. Nesting of layers in a multilayer stack is an important phenomenon which not only effect the stack thickness [26] but also effect the resin permeability during composite manufacturing [30] and mode 1 fracture toughness [33]. Based upon these facts the quantification of nesting is important. In this study, the nesting of the layers was calculated in terms of nesting factor (NF) for multilayer stacks using test results obtained from the compaction of dry preform on Instron testing machine. Figures 12 and 13 represents the results of nesting factors calculated for woven and non-crimp stitched fabrics.
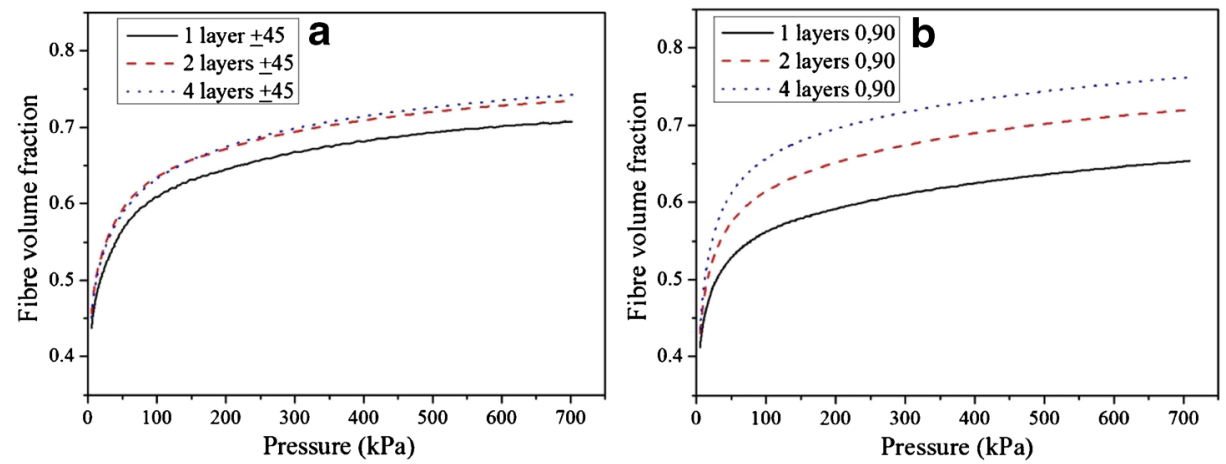

Fig. 10 Fibre volume fraction of non-crimp carbon fibre fabric as a function of pressure, $\mathbf{a} \pm 45^{\circ}, \mathbf{b} 0^{\circ}, 90^{\circ}$ 

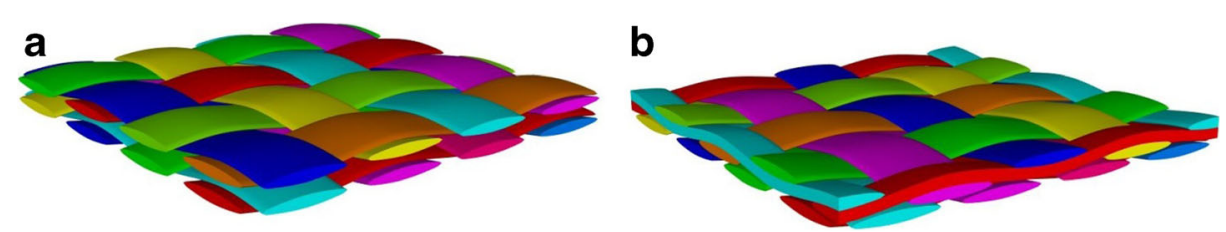

Fig. 11 Two layer fabric stack $\mathbf{a}$ with out layer shifting and nesting and $\mathbf{b}$ with layer shifting and nesting

In the case of woven fabrics, it was observed that the nesting factors are lower for plain woven fabrics, reflecting better nesting compared to twill and sateen fabrics. The least nesting was observed for sateen fabric. Higher nesting in plain woven fabrics can be attributed to a shorter float length which allows better nesting. On the other hand, the sateen fabric, which has the largest float length, have minimum nesting. This observation agrees with the study of Lomov et al. [26], according to which the presence of longe yarn floats results in lower nesting and vice versa. As already mentioned in the discussion of results of woven fabrics that least fabric thickness reduction was witnessed in plain fabrics, in both single and multilayer cases. Whereas, better nesting is observed in plain fabric compared to twill and sateen fabrics during nesting factor calculations. Better nesting in plain multilayer fabrics should result into reduced stack thickness of plain fabric compared to multilayer twill and sateen fabrics but opposite behaviour was noticed. The reason for higher stack thickness of the plain woven fabric, even in presence of higher nesting can be attributed to least bending deformation of plain woven fabric
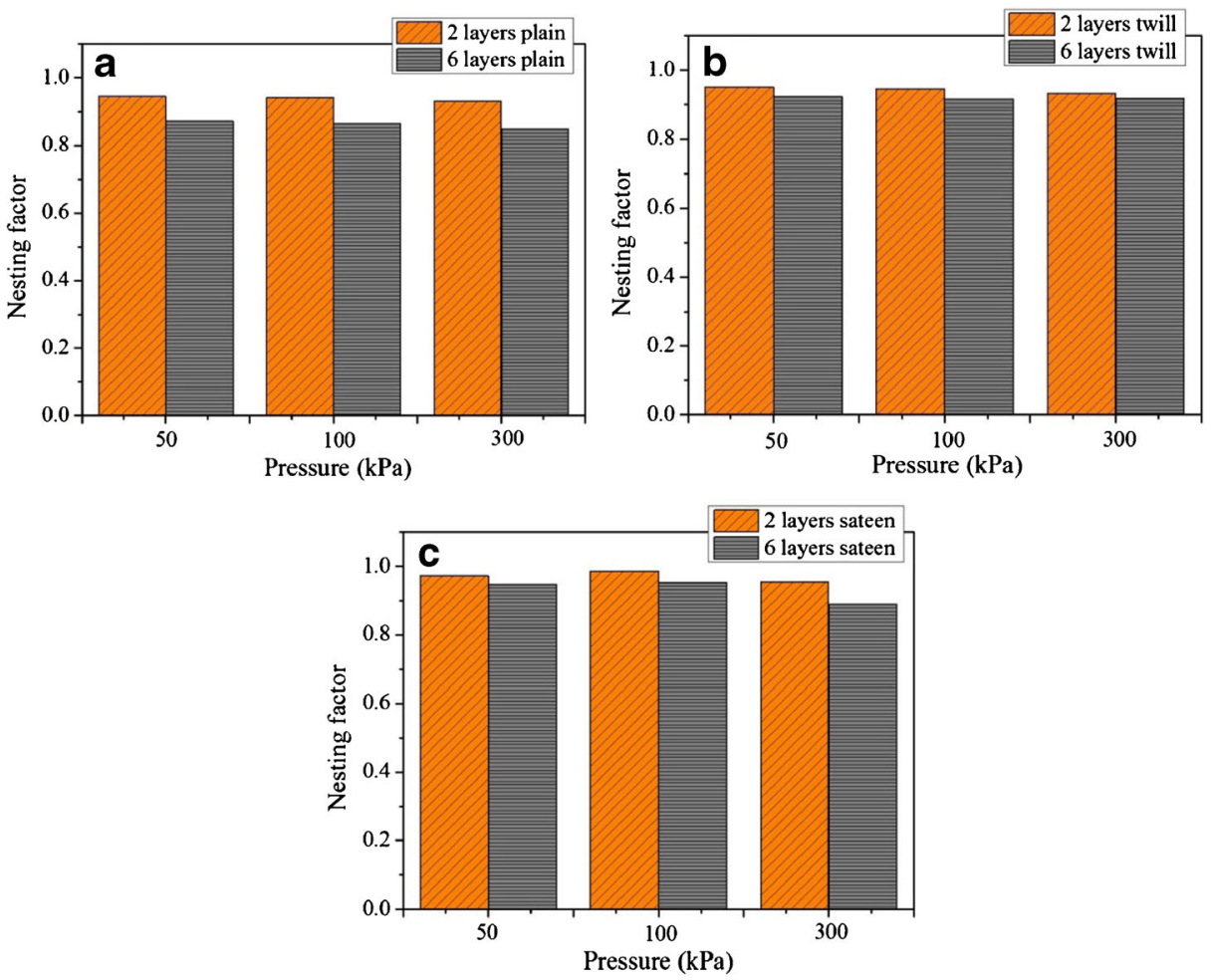

Fig. 12 Nesting factors for woven fabrics a plain fabrics $\mathbf{b}$ twill fabric and $\mathbf{c}$ sateen fabrics 

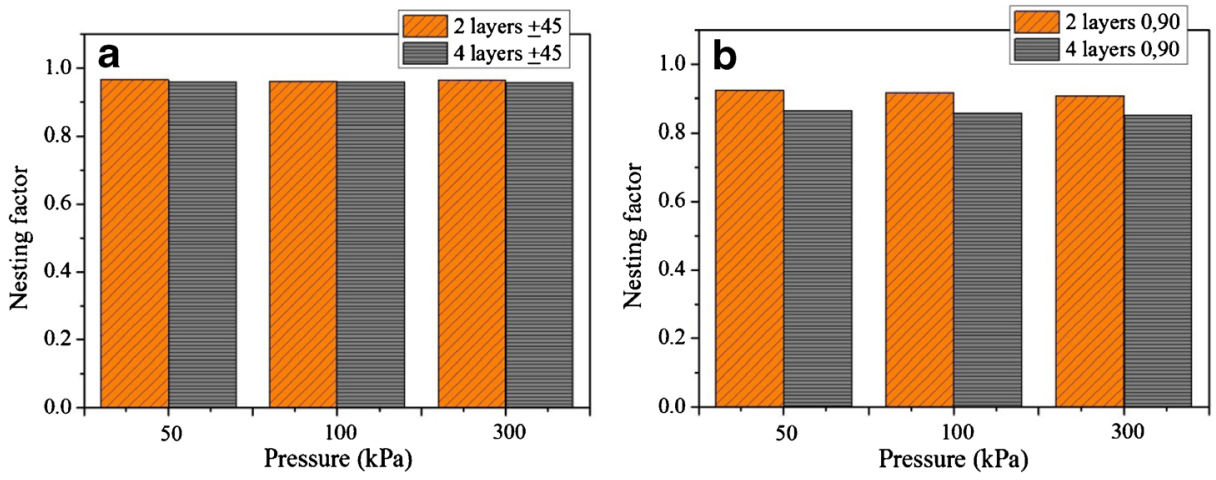

Fig. 13 Nesting factors for $\mathrm{NCF} \mathbf{a} \pm 45^{\circ} \mathbf{b} 0^{\circ}, 90^{\circ}$

due to the tight structure of plain fabrics. Whereas, in twill and sateen fabric, due to loose structure of these fabrics, higher bending deformation occurs which dominants even in presence of better nesting effect in plain fabrics giving relatively lower stack thickness of twill and sateen fabrics.

For non-crimp fabrics, the calculated nesting factor results are lower for $0^{\circ}, 90^{\circ}$ (Fig. 13) indicating better nesting in the case of $0^{\circ}, 90^{\circ}$ compared to the $\pm 45^{\circ}$ configuration. Again the reason of better nesting in $0^{\circ}, 90^{\circ}$ can be returned to the presence of coarser stiched yarn on the fabric surface of $0^{\circ}, 90^{\circ}$ fabric compared to $\pm 45^{\circ}$ fabric as discussed in Section 3.1.2. Also, the shifting pattern of the layers during lay-up, plays an important role in nesting. In ideal situations, the shifting of the layers should also be considered using structural analysis during nesting comparison so as to give a better understanding of the nesting phenomenon. From overall nesting study of woven and non-crimp fabrics, plain woven fabrics exhibited the highest nesting which can be attributed to the presence of shortest float length in plain woven fabrics [26].

\section{Conclusions}

In this work, 2D woven fabrics of different interlacement patterns with identical tows and tow spacing were developed and tested for compaction behaviour. Non-crimp fabrics with two different tow orientations were also included in the study.

The following key conclusions can be made from the compressive study of the fabrics at macro level.

- In transverse compaction of plain, twill and sateen fabrics, the thickness of the plain weave fabric is lowest at the onset of loading which might be due to interlacement forces on the plain weave during the manufacturing process as the plain weave has the highest number of interlacements per unit area compared to twill and sateen weaves.

- During compression, the highest thickness reductions occured for the twill and sateen fabrics. This is attributed to the larger float length of the weaves which results in loose structure of these weaves, giving more bending deformation of the tows during compaction.

- Better nesting is present in plain fabric compared to twill and sateen but during compaction of multilayer stack of these weaves, the bending deformation contributes more towards thickness reduction than the nesting of the layers. 
- For the non-crimp fabrics (NCF), the thickness reduction is largest for the $0^{\circ}, 90^{\circ}$ fabric (14\% thickness reduction for 4 layers at $600 \mathrm{kPa}$ ) compared to $\pm 45^{\circ}$ fabric ( $4 \%$ thickness reduction for 4 layers at $600 \mathrm{kPa}$ ) which might be due to the presence of thick yarn on the fabric surface of $0^{\circ}, 90^{\circ}$ fabric and the round shape of the tows due to different thread spacing in $0^{\circ}, 90^{\circ}$ allowing better inter-tow nesting.

Acknowledgments The first author gratefully acknowledges Bahauddin Zakariya University Multan, Pakistan for funding his $\mathrm{PhD}$ research work.

Open Access This article is distributed under the terms of the Creative Commons Attribution 4.0 International License (http://creativecommons.org/licenses/by/4.0/), which permits unrestricted use, distribution, and reproduction in any medium, provided you give appropriate credit to the original author(s) and the source, provide a link to the Creative Commons license, and indicate if changes were made.

\section{References}

1. Yang, B., Kozey, V., Adanur, S., Kumar, S.: Bending, compression, and shear behavior of woven glass fiber-epoxy composites. Compos. Part B 31(8), 715-721 (2000)

2. Yu, B., James Lee, L.: A simplified in-plane permeability model for textile fabrics. Polym. Compos. 21(5), 660-685 (2000)

3. Robitaille, F., Gauvin, R.: Compaction of textile reinforcements for composites manufacturing. I: Review of experimental results. Polym. Compos. 19(2), 198-216 (1998)

4. Pearce, N., Summerscales, J.: The compressibility of a reinforcement fabric. Compos. Manuf. 6(1), 15-21 (1995)

5. Matsudaira, M., Qin, H.: Features and mechanical parameters of a fabric's compressional property. J. Text. Inst. 86(3), 476-486 (1995)

6. Chen, B., Chou, T.-W.: Compaction of woven-fabric preforms in liquid composite molding processes: single-layer deformation. Compos. Sci. Technol. 59(10), 1519-1526 (1999)

7. Chen, B., Chou, T.-W.: Compaction of woven-fabric preforms: nesting and multi-layer deformation. Compos. Sci. Technol. 60(12-13), 2223-2231 (2000)

8. Chen, B., Lang, E.J., Chou, T.-W.: Experimental and theoretical studies of fabric compaction behavior in resin transfer molding. Mater. Sci. Eng. A 317(1-2), 188-196 (2001)

9. Chen, B., Cheng, A.H.D., Chou, T.W.: A nonlinear compaction model for fibrous preforms. Compos. A: Appl. Sci. Manuf. 32(5), 701-707 (2001)

10. De Jong, S., Snaith, J.W., Michie, N.A.: A mechanical model for the lateral compression of woven fabrics. Text. Res. J. 56(12), 759-767 (1986)

11. Saunders, R.A., Lekakou, C., Bader, M.G.: Compression and microstructure of fibre plain woven cloths in the processing of polymer composites. Compos. A: Appl. Sci. Manuf. 29(4), 443-454 (1998)

12. Simacek, P., Karbhari, V.M.: Notes on the modeling of preform compaction: I -Micromechanics at the fiber bundle level. J. Reinf. Plast. Compos. 15(1), 86-122 (1996)

13. Chen, Z.-R., Ye, L., Kruckenberg, T.: A micromechanical compaction model for woven fabric preforms. Part I: Single layer. Compos. Sci. Technol. 66(16), 3254-3262 (2006)

14. Chen, Z.-R., Ye, L.: A micromechanical compaction model for woven fabric preforms. Part II: Multilayer. Compos. Sci. Technol. 66(16), 3263-3272 (2006)

15. Potluri, P., Parlak, I., Ramgulam, R., Sagar, T.V.: Analysis of tow deformations in textile preforms subjected to forming forces. Compos. Sci. Technol. 66(2), 297-305 (2006)

16. Van Wyk, C.M.: Note on the compressibility of wool. J. Text. Inst. 37(12), T285-T292 (1946)

17. Saunders, R.A., Lekakou, C., Bader, M.G.: Compression in the processing of polymer composites 1 . A mechanical and microstructural study for different glass fabrics and resins. Compos. Sci. Technol. 59(7), 983-993 (1999)

18. Hammami, A.: Effect of reinforcement structure on compaction behavior in the vacuum infusion process. Polym. Compos. 22(3), 337-348 (2001)

19. Luo, Y., Verpoest, I.: Compressibility and relaxation of a new sandwich textile preform for liquid composite molding. Polym. Compos. 20(2), 179-191 (1999) 
20. Kim, Y.R., McCarthy, S.P., Fanucci, J.P.: Compressibility and relaxation of fiber reinforcements during composite processing. Polym. Compos. 12(1), 13-19 (1991)

21. Kruckenberg, T., Ye, L., Paton, R.: Static and vibration compaction and microstructure analysis on plainwoven textile fabrics. Compos. A: Appl. Sci. Manuf. 39(3), 488-502 (2008)

22. Lomov, S.V., Belov, E.B., Bischoff, T., Ghosh, S.B., Truong Chi, T., Verpoest, I.: Carbon composites based on multiaxial multiply stitched preforms. Part 1 . Geometry of the preform. Compos. A: Appl. Sci. Manuf. 33(9), 1171-1183 (2002)

23. Lomov, S.V., Verpoest, I., Barburski, M., Laperre, J.: Carbon composites based on multiaxial multiply stitched preforms. Part 2. KES-F characterisation of the deformability of the preforms at low loads. Compos. A: Appl. Sci. Manuf. 34(4), 359-370 (2003)

24. Liu, X.L., Falzon, P.J., Sweeting, R., Paton, R.: Effective compressibility and permeability of multi-layer non-crimp fiberglass reinforcements. J. Reinf. Plast. Compos. 23(8), 861-879 (2004)

25. Lomov, S.V., Barburski, M., Stoilova, T., Verpoest, I., Akkerman, R., Loendersloot, R., Thije, R.H.W.T.: Carbon composites based on multiaxial multiply stitched preforms. Part 3: Biaxial tension, picture frame and compression tests of the preforms. Compos. A: Appl. Sci. Manuf. 36(9), 1188-1206 (2005)

26. Lomov, S.V., Verpoest, I., Peeters, T., Roose, D., Zako, M.: Nesting in textile laminates: geometrical modelling of the laminate. Compos. Sci. Technol. 63(7), 993-1007 (2003)

27. Grujicic, M., Chittajallu, K.M., Walsh, S.: Effect of shear, compaction and nesting on permeability of the orthogonal plain-weave fabric preforms. Mater. Chem. Phys. 86(2-3), 358-369 (2004)

28. Senoguz, M.T., Dungan, F.D., Sastry, A.M., Klamo, J.T.: Simulations and experiments on low-pressure permeation of fabrics: Part IIâ€” The variable gap model and prediction of permeability. J. Compos. Mater. 35(14), 1285-1322 (2001)

29. Dungan, F.D., Senoguz, M.T., Sastry, A.M., Faillaci, D.A.: Simulations and experiments on low-pressure permeation of fabrics: Part I-3D modeling of unbalanced fabric. J. Compos. Mater. 35(14), 1250-1284 (2001)

30. Hoes, K., Dinescu, D., Sol, H., Parnas, R.S., Lomov, S.: Study of nesting induced scatter of permeability values in layered reinforcement fabrics. Compos. A: Appl. Sci. Manuf. 35(12), 1407-1418 (2004)

31. Potluri, P., Sagar, T.V.: Compaction modelling of textile preforms for composite structures. Compos. Struct. 86(1-3), 177-185 (2008)

32. Lomov, S.V., Gorbatikh, L., Kotanjac, Z., Koissin, V., Houlle, M., Rochez, O., Karahan, M., Mezzo, L., Verpoest, I.: Compressibility of carbon woven fabrics with carbon nanotubes/nanofibres grown on the fibres. Compos. Sci. Technol. 71(3), 315-325 (2011)

33. Olave, M., Vara, I., Husabiaga, H., Aretxabaleta, L., Lomov, S.V., Vandepitte, D.: Nesting effect on the mode I fracture toughness of woven laminates. Compos. A: Appl. Sci. Manuf. 74, 166-173 (2015) 